\title{
Sublingual Crescent Extension: A Solution for Loose Lower Denture-A Case Report
}

\author{
Nishna Pradeep and Jinsa P Devassy*
}

Department of Prosthodontics, Kannur Dental College, Kerala, India

\begin{abstract}
Mandibular complete dentures frequently lack retention and stability and offer less denture-supporting area than maxillary dentures. In case of severely resorbed ridges retention is highly compromised. Extending the anterior lingual flange of the lower denture sublingually makes it possible to achieve satisfactory retention in severely resorbed ridges. This clinical report describes a simpler method to achieve retention during impression making and thus help to maintain the retention and stability of lower dentures during function.
\end{abstract}

Keywords: Resorbed ridges; Sublingual crescent extension; Mandibular denture

\section{Introduction}

Achieving retention and stability in lower complete denture with a severely resorbed ridge is still a challenging one for the general dentist [1]. Here introducing a simple solution for loose lower denture which gives excellent retention and stability to normal or medium height ridges and satisfactory retention in severely resorbed ridges, where otherwise achieving retention is a dream.

Though many terms have been given to the regions covered by sublingual flange, the appropriate term is sublingual crescent because it describes the region from both anatomic and topical aspects.

According to the Glossary of Prosthodontic terms sublingual crescent area (Figure 1) is the crescent shaped area on the anterior floor of the mouth formed by the lingual wall of the mandible and the adjacent sublingual fold. Sublingual crescent extension is defined as the portion of the sublingual flange of the mandibular denture that covers the anterior region of floor of the mouth [2].

\section{Case Report}

A 63 year old female patient reported to the Department of Prosthodontics, Kannur dental college with a chief complaint of looseness of lower denture since 6 years. Her history revealed that she was edentulous for 20 years and a denture wearer for 19 years. Medical history revealed she was a known diabetic for past 25 years. The intra oral examination revealed completely edentulous maxillary and mandibular arch with considerable resorption in lower anterior region. Keeping the various challenges associated with the case, clinical steps and treatment plan was modified to give a mandibular complete denture with sublingual crescent extension opposing a conventional maxillary denture.

\section{Technique}

Primary impression was made by irreversible hydrocolloid in perforated stock tray. Special tray was fabricated on primary cast without using spacer [1]. After special tray extensions were corrected, border moulding with low fusing compound was done in the conventional manner starting from the distolingual sulcus (Figure 2). The labial and buccal areas were then border moulded (Figure 3). Sublingual recording was initiated with impression compound. The impression compound was softened in hot water $\left(60^{\circ} \mathrm{C}\right)$ and added into borders of custom acrylic resin tray from premylohyoid, from one side to the other (Figure 4). The added compound was then tempered in hot water; the special tray was placed in patient's mouth. The patient was instructed to gently place the tongue against the lingual side of tray handle. The tray was removed from mouth and cooled in cold water. This procedure was repeated until the sublingual crescent area was recorded satisfactorily. The impression compound was relieved in frenal notch area to expose the openings of sublingual ducts. The low fusing compound was carefully added along the borders of the recorded sublingual crescent in impression compound and patient was asked to repeat the same movement. The added sublingual crescent extension now maintains contact with the sublingual fold when tongue touches the lower lip (Figure 5). It also maintains contact with floor of mouth even when tongue is in retracted position, thereby developing a good peripheral seal. Relief holes were made in the special tray and the secondary impression was made with zinc oxide eugenol impression paste (Figure 6). Remaining steps were done in the conventional manner and the denture was fabricated in heat cure acrylic resin using long curing cycle (Figure 7).

\section{Discussion}

In case of severely resorbed ridges the factors affecting retention are

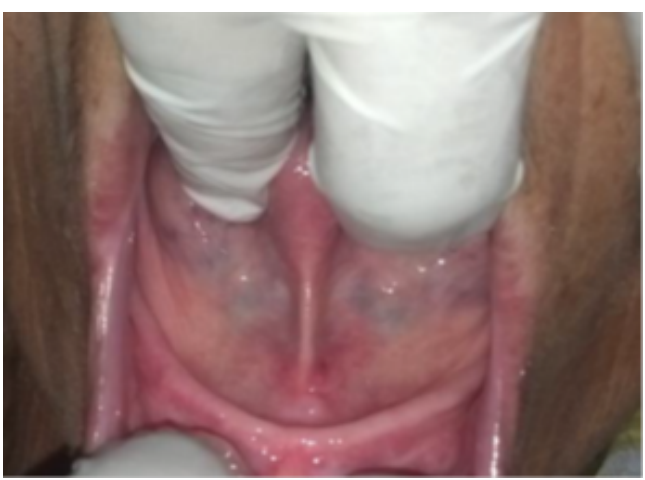

Figure 1: Sublingual crescent area.

*Corresponding author: Jinsa $\mathrm{P}$ Devassy, Department of Prosthodontics, Kannur Dental College, Kerala, India, Tel: +91-0-497 2700 593; E-mail: jinsa.pd@gmail.com

Received March 16, 2015; Accepted April 11, 2015; Published April 15, 2015

Citation: Pradeep N, Devassy JP (2015) Sublingual Crescent Extension: A Solution for Loose Lower Denture-A Case Report. Dentistry 5: 295. doi:10.4172/2161 1122.1000295

Copyright: ( 2015 Pradeep N, et al. This is an open-access article distributed under the terms of the Creative Commons Attribution License, which permits unrestricted use, distribution, and reproduction in any medium, provided the original author and source are credited. 
Citation: Pradeep N, Devassy JP (2015) Sublingual Crescent Extension: A Solution for Loose Lower Denture-A Case Report. Dentistry 5: 295. doi:10.4172/2161-1122.1000295

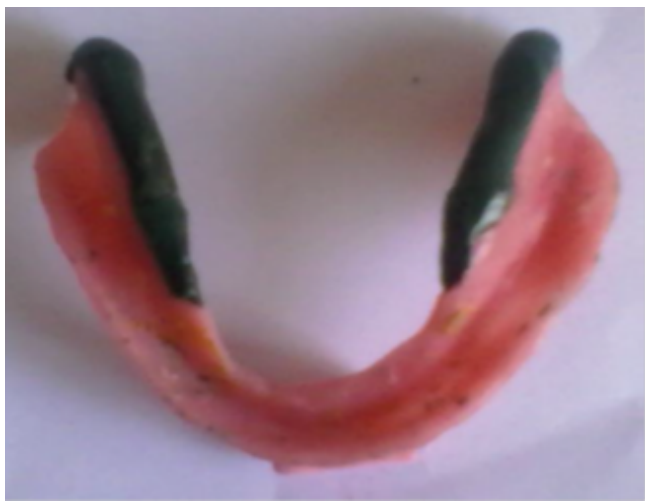

Figure 2: Border moulding done with low fusing compound starting from the distolingual sulcus.

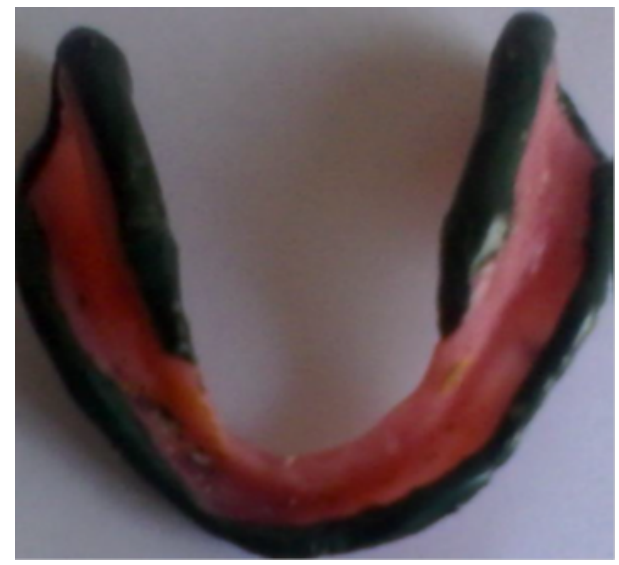

Figure 3: The labial and buccal areas were then border moulded.

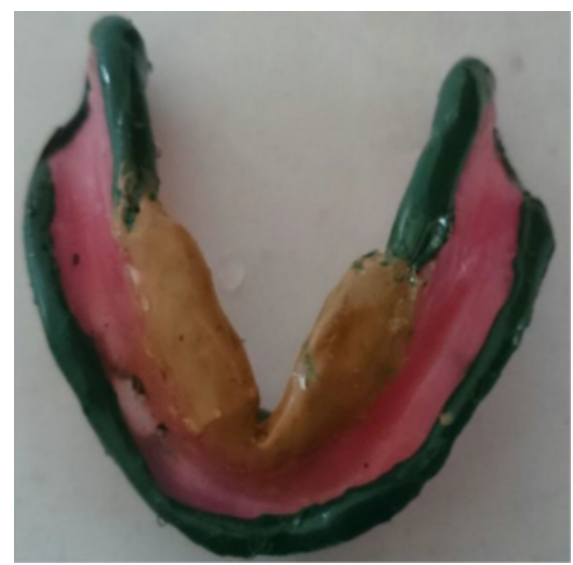

Figure 4: The impression compound added into borders of custom acrylic resin tray from premylohyoid.

highly compromized. Lewis ET [3] was first to report about the anterior sublingual area anatomy and utilization of sublingual crescent space for the retention of mandibular denture. Many of the problems that arise during the course of denture construction can be solved easily through knowledge of anatomy and anatomic landmarks. Lewis, in his article states that the most important area for retention of the lower denture is the anterior lingual region, from cuspid to cuspid. We must examine this area thoroughly and, according to its character, learn to evaluate the mandible and the floor of the mouth for the construction of a good denture. Mandibular complete dentures frequently lack retention and stability and offer less denture-supporting area than maxillary dentures. A sublingual flange extension improves the retention and stability of complete lower dentures. It increases the tissue surface of the denture, augmenting simple adhesion and, therefore, retention. Krammer and Lawson $[4,5]$ describe the principles and techniques of sublingual crescent extension and suggested its utilization in distal- extension

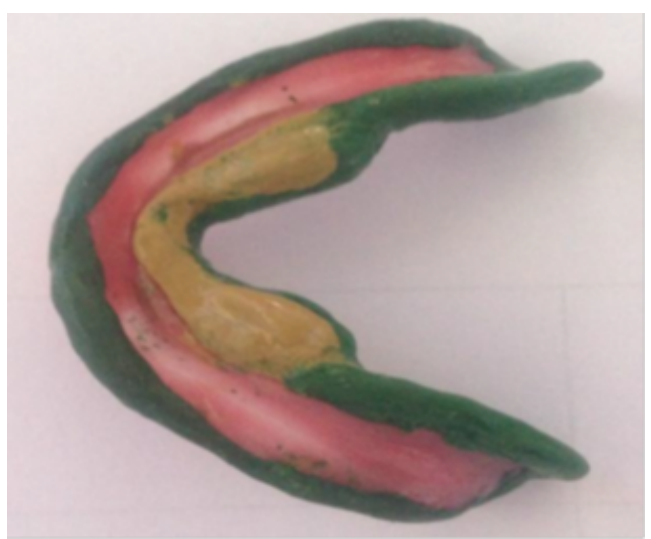

Figure 5: The added sublingual crescent extension

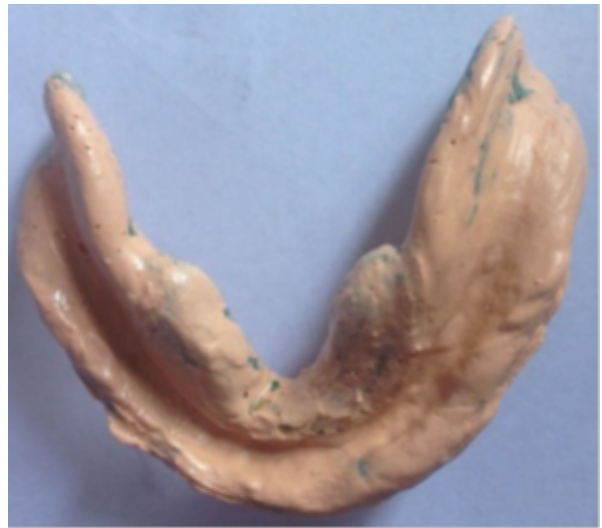

Figure 6: Relief holes made in the special tray and the secondary impression

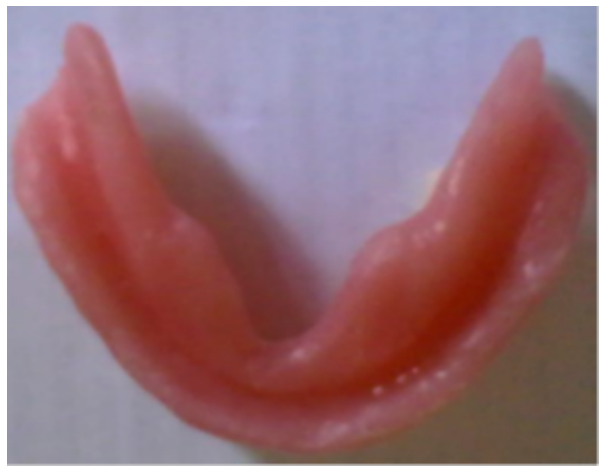

Figure 7: The fabricated denture. 
Citation: Pradeep N, Devassy JP (2015) Sublingual Crescent Extension: A Solution for Loose Lower Denture-A Case Report. Dentistry 5: 295. doi:10.4172/2161-1122.1000295

lower partial dentures also. Azzam et al. [2] describe the importance and clinical procedure for sublingual crescent extension. In his article he reports that upon completion of the sublingual crescent border, evidence of enhanced resistance to dislodgment is usually achieved and the denture is more stable during normal tongue movements such as swallowing, speaking, and eating. Over extended sublingual crescent extension will diminish the denture retention [6]. The size and position of sublingual folds vary considerably in different patients. Some are large and well developed, whereas others are much smaller, particularly in elderly patients in whom degenerative changes have occurred. The smaller the fold, the poorer are the chances of complete success and the greater become the care required to achieve the necessary contact with the mucosa of the floor of the mouth ${ }^{5}$ In this modern era implants can help to increase the retention and stability, but in cases where it cannot be done, sublingual crescent extension offers a simpler alternative. In this case we didn't use patient's past denture because it was ill fitting and can't use an impression tray. The material of choice of sublingual crescent extension is modeling compound [4]. One requirement of the sublingual extension of the impression is to have minimal pressure exerted on the floor of the mouth with the tongue at rest. Minimal pressure may be described as the weight of the softened modeling compound. Excess pressure will occlude the opening of the sublingual gland ducts with swelling of the tissues. ${ }^{2}$ In our case we reviewed the patient after one week, two week and four week, patient was very satisfied with the denture and on examination no swelling or ulcer seen in any area.

\section{Conclusion}

This is a very simple technique which can be easily incorporated in our day to day clinical practice to enhance retention of mandibular dentures especially in resorbed ridges.

\section{References}

1. Gafoor MA, Kumar VV, Sheejith M, Swapna C (2012) Recording sublingual crescent in lower complete denture: a technique so effective but still esoteric and arcane. The journal of contemporary dental practice 13: 222-226.

2. Azzam MK, Yurkstas AA, Kronman J (1992) The sublingual crescent extension and its relation to the stability and retention of mandibular complete dentures. J Prosthet Dent 67: 205-210.

3. Lewis ET (1958) Repositioning of the sublingual fold for complete dentures. J Prosthet dent 8: 22-25

4. von Krammer R (1982) Principles and technique in sublingual flange extension and complete mandibular dentures. J Prosthet Dent 47: 479-482.

5. A Lawson (1961) Influence of the sublingual fold on retention of complete lower dentures. J Prosthet dent 11: 1038-1044.

6. Chang JJ, Chen JH, Lee HE, Chang HP, Chen HS, et al. (2011) Maximizing mandibular denture retention in the sublingual space. Int $\mathrm{J}$ Prosthodont 24 460-464. 